\title{
DISERTACIONES Y DESCUBRIMIENTOS EN VIAJE EN ESPAN $A$ DE RAFAEL SANHUEZA LIZARDI
}

\author{
Javier López Quintáns \\ IES «Ramón María Aller Ulloa» (Lalín)
}

\begin{abstract}
Resumen: Viaje en España, texto de Rafael Sanhueza Lizardi, aparece en el año 1884. Con él realiza un recorrido por Cataluña, Valencia y llega finalmente a Andalucía, donde visita Granada, Córdoba o Sevilla. El artículo analiza sus características de libro de viajes, y las numerosas referencias culturales e intertextuales que en él aparecen.
\end{abstract}

Palabras clave: Sanhuez Lizardi, libro de viajes, intertextualidad, Chile, España.

Abstract: Travel in Spain, Rafael Sanhueza Lizardi text, appears in the year 1884. It offers a tour of Catalonia, Valencia and finally comes to Andalusia, where he visits Granada, Cordoba and Seville. The article discusses its characteristics as a travel book, and numerous cultural and intertextual references that appear in it.

Keywords: Sanhueza Lizardi, travel book, intertextuality, Chile, Spain.

Viaje en España, texto de Rafael Sanhueza Lizardi que aparece en el año 1884, forma parte de la literatura de viajes que se aproxima a España desde un presupuesto falaz: el descubrimiento de la tierra a partir de un postulado primigenio y neófito, inocente y desangelado. Es falaz por lo que supone de sesgado por creencias que circulaban de manera persistente durante décadas. Junto a estos tópicos, la abundante producción de narrativa de viajes pesa sobre la composición del texto. Por una parte, porque algunas de estas obras refundían testimonios previos (y en ocasiones erróneos) sobre la península, con casos peculiares en los que el autor, sin visitar la zona, afirmaba sus peripecias por el lugar parafraseando datos ajenos. Por otra parte, la trayectoria discursiva de sus predecesores motiva y condiciona las incursiones diegéticas del viajero: Jean Francois Bourgoing, Teófilo Gautier, Dumas, madame D’Aulnoy, Joseph Townsend, George Borrow o Washington Irving son solamente unos pocos nombres de los que por tierras peninsulares se aventuraron ${ }^{1}$.

1 Véanse Raymond Foulche-Delbosc (1991), Bibliographie des voyages en Espagne et Portugal; Carlos García-Romeral Pérez (1995), Bio-biliografía de viajeros españoles (siglo XIX) y 
El viajero asume la tradición anterior y la imita, en un afán mimético que aspira a la integración plena en un género ya canónico. Pero lo hace en lo que atañe a la distribución estructural (orden cronológico y desarrollo lineal) y el uso de ciertos resortes y recursos (se apoya en la anécdota y en las impresiones populares para dinamizar la exposición). Sin embargo, el autor muestra un rigor llamativo y una precisión cuidada en el detalle de lo que contempla, con lo que se otorga un inestimable valor documental al texto. Tiene mucho que ver con el tipo de viaje que emprende, de corte intelectual (no sesgado por intenciones religiosas, económicas o de cualquier otro índice moral, como podemos extraer de la clasificación expuesta por Bordonada, 1995); implica por tanto un recreamiento autoformador y una mesurada actividad de interpretación de un entorno lejano, de comunicación de lo vivido y de exposición de los conocimientos eruditos que adquiere. El enfrentamiento entre lo propio y lo ajeno, de asunción de las peculiaridades del otro (netamente presente en la literatura de viajes), se manipula con deliberada mesura y juiciosa contención, que nos permite admirar a un Sanhueza Lizardi desprovisto de enojosos prejuicios (incluso ante temas polémicos que a él mismo desagradan, caso de las lidias taurinas). Aplica así una necesaria actitud alienizante (según lo explica Gasquet, 2006: 49) que no impide que tienda puentes con su tierra.

Con Lizardi, advertimos un elemento que juega a favor y otro que lo perjudica: a su favor pesa que proceda de allende los mares y se mantenga levemente distanciado de la tradición europea, ricamente sembrada en disertaciones, excursos deturpados y rincones tópicos sobre el viaje a España. Pero al mismo tiempo, en contra, se percibe cierto afán de imitación que no busca más que reafirmar su condición de intelectual. Ambos, aunque parezcan en contradicción intima, contribuyen en realidad a la originalidad del texto: la distancia geográfica, pese a la tan cacareada hermandad de naciones, favorece el contraste cultural; la tradición previa provoca una imitación más o menos fallida.

\section{Motivaciones}

La descripción de las razones que mueven a Lizardi entroncan con algunas de las viejas aspiraciones de la cultura hispanoamericana en el panorama decimonónico. Virtud a ello, aparece la manoseada imagen de la vieja Europa como punto soñado y objetivo de los jóvenes instruidos, en gran parte de la alta burguesía. En tanto que ingrediente de su formación, el viaje al continente constituía un elemento insustituible, bajo la aureola mitificada del grand tour, el itinerario que emprendía desde el siglo XVIII la elite inglesa. Durante períodos que rondaban lo dos años, recorrían el continente para completar una adecuada instrucción. Con el viaje, además, solidificaban, previo manejo de recomendaciones y cartas de presentación, necesarios contactos para después emprender

Bio-bibliografía de viajeros por España y Portugal (siglo XIX). 
su vida de adultos y concretar su prosperidad económica. Para ello, se acompañaban de servicio y un abultado equipaje con el que satisfacer las necesidades de tales incursiones. Entre las paradas inexcusables figuraba Italia, considerada cuna de occidente, pero España gana con el tiempo adeptos y acaba formando parte de ese mapa ineludible de incursiones elitistas.

El modelo del grand tour europeo disfruta de una imitación sui generis allende los mares a medida que prospera la burguesía en el poder, la burguesía que controlaba las jóvenes naciones hispanoamericanas. Como afirma Aínsa (2008: 50), esta confrontación identitaria resultó fundamental entre 1880 y la Gran Guerra de 1914-1918 en la formación de escritores y artistas. En el origen fueron señoritos e intelectuales chilenos y rioplatenses los que consideraron que un viaje a Europa era parte ineludible de su formación.

El concepto de madre patria, en precavida admiración asimilada con una contención recelosa, se arguye como pieza de peso: "Para nosotros una visita a España era casi una necesidad primordial, la satisfacción de uno de los más vivos deseos que nos obligaron a clausurar por breve plazo nuestro modesto taller $(. .$. (Viaje en España —en adelante VE-, pág. 1)”.

$\mathrm{El}$ texto que ahora nos ocupa maneja las cortapisas a tan sugerente viaje, muy relacionadas con otro elemento tópico en el mundo del siglo XIX: la leyenda negra sobre una España atávica, atrasada, sumida en disputas entre carlistas y fuerzas del gobierno, en un atraso impúdico frente a, por ejemplo, la resplandeciente y vivaz París. Junto al testimonio del viaje el autor se recrea en una delectación expositiva que busca mostrar al narrador labrado y culto referencias intelectuales en conexión con los lugares que se visitan, a la par que recurre a ciertas licencias para aproximarse al público más popular: así nos lo sugieren las rememoraciones de aromas en jardines, imágenes en monumentos y placeres posibles en la visita a París, junto al tono conversacional de gran parte de los diálogos que se reproducen. Si volvemos sobre lo dicho, es precisamente la imagen de la madre patria que antes mencionábamos la que contribuye a la visita a España, como referente basal de hispanoamérica. Así pues, el autor pasa casi de puntillas por su visita a otras regiones europeas como Francia, para luego emprender la visita a España desde Barcelona. Sanhueza Lizardi, político e intelectual chileno (1852-1902), emprende un camino de descubrimiento que nos lega alguna de las estampas más llamativas de la España de las últimas décadas del XIX.

La madre patria, raíz de hispanoamérica, atrae al viajero, que inmediatamente manifiesta sus reparos. Con esta tónica Lizardi se balancea en una postura equilibrada entre la defensa de España frente a la descripción negativa, y por otra parte el ajuste de cuentas con respecto al pasado de opresión colonial. La defensa se sustenta en la negación de los reproches generalizados, sin justificación sólida (p. 31), sin que ello obvie el atraso absurdo (frente a una Europa en pleno desarrollo y ebullición) que padece en infraestructuras y medios de transporte. 
Con sus palabras, reivindica los años perdidos de las naciones americanas bajo el yugo colonial. Busca entonces un peculiar ajuste de cuentas en el que reivindica la peculiaridad hispanoamericana y su emancipación con respecto a la metrópolis, al mismo tiempo que reniega de la opresión padecida durante siglos. Estos elementos condimentan la peculiaridad del texto. Otros viajeros, los europeos fundamentalmente, se manifestaban desde cierto distanciamiento paternalista, y cierta inclinación hacia un pintoresquismo que atrae desde una visión muchas veces tópica y nítidamente folclórica. Sin embargo, Lizardi mantiene de modo mayoritario una equidistancia que atropella a conveniencia, como ajuste de cuentas necesario ante la nación con la que se entabla una relación conflictiva de respeto y necesaria reivindicación. Por ello, censura el impenitente carácter español que tiende a menospreciar lo propio en beneficio de lo que de fuera llega.

\section{Observación neutral}

El testimonio de Lizardi busca en muchos casos la mera enumeración distanciada, bajo el pelaje de observador neutral que transcribe lo que ve. Como ocurre en la literatura de viajes, ofrece una estructura descriptiva que implica una actitud contemplativa del lector (a juicio de Carrizo Rueda, 1997).

Así surgen los paisajes españoles una vez se crucen los Pirineos, las vislumbres del Mediterráneo o la vegetación catalana. Para él merecen detalle los diferentes cultivos en las zonas que atraviesa, como la huerta valenciana y sus aromas afrutados. El poder económico de Cataluña, a través de sus pujantes manufacturas y las vivaces ciudades, supone un comienzo propiciatorio del viaje. Con sus incursiones conocemos las paradas fundamentales en cada lugar, como el Liceo, las Ramblas, las plazas y los parques, en Barcelona. El caso específico de Las Ramblas muestra la descripción neutral que se mencionaba, desde una visión genérica hasta la delimitación de los detalles:

a. Longitud del espacio (en cuadras).

b. Disposición de los plataneros en las esquinas y zonas de la alameda (San Francisco, O’Higgins, Santa Mónica, Capuchinos San José, Estudios y Canaletas).

c. Distribución de lugares de ocio y hostelería.

Igual afán distanciador, embebido de una intención laudatoria, se aprecia en la certificación de la pujanza de la lengua catalana. De notable interés es el testimonio de un chileno sobre literatura catalana: Pi i Margall, Balaguer, Verdaguer o Fortuny se enumeran en sus páginas, y sobre todo Federico Soler y Narciso Oller. La observación desangelada se constata en el número de instituciones que componen el espectro sociocultural del lugar que se visita, sin que se profundice en las características de dichas entidades. Se convierte esta en una constante en la obra, la simple retahíla que, ocasionalmente, se complementa con alguna 
apostilla descriptiva: hablamos de la Academia de Buenas Letras, la Taquigrafía, la Sociedad Catalana de Gas o el Instituto Industrial de Cataluña en Barcelona.

Como en la ciudad condal, se detiene en la descripción geofísica de las distintas urbes que visita. En Valencia, contemplamos los barrios en las zonas antigua y nueva, el puerto, los ocho cuarteles de la huerta, el teatro de las Comedias, pero también la Albufera. Con Córdoba, que le provoca un notorio desencanto (ante las expectativas que no se han cumplido), describe la típica casa enrejada y sus estrechas callejuelas, mientras que en Gibraltar nos presenta la plana y el peñón o en Málaga conocemos sus callejuelas.

En este apartado conviene mencionar el interés por las labores industriales y las iniciativas de los empresarios. En efecto, le motivan las fábricas y las manufacturas que producen, o la labor esmerada de las carpinterías (p. 33). Subrayemos que Lizardi se aleja de las grandes urbes (protagonistas, sí, de la mayoría de páginas) y se detiene en pequeños pueblos, como los catalanes Cots y San Martín.

Con la observación neutral percibimos el empeño del autor por precisar cifras, en especial en lo que toca a dimensiones de terrenos o edificaciones (lo especifica en yardas, cuadras, aplicando su específica dimensión del mundo en el continente añejo al que ha llegado). Con Lizardi anotamos un deliberado afán cultural, un prurito erudito que busca la precisión continua de datos y alusiones históricas. La efeméride se convierte en herramienta auxiliar con la que se completa la visita, sirviendo asimismo de mecanismo de instrucción del lector. Tomemos las referencias a los Borbones y su papel en Cataluña o el trágico sitio de Sagunto; de Córdoba extrae la semblanza de Averroes, Séneca o el Gran Capitán; en Sevilla, menciona a los reyes que allí tuvieron su cuna, como Enrique II y Fernando IV, o geniales artistas de la talla de Lope de Rueda, Murillo o Velázquez (todo ello debidamente sazonado con leyendas y rememoraciones populares: la historia de la cabeza cortada y el rey Pedro el cruel o los escarceos amorosos de este mismo con María de Padilla son llamativa muestra de la referencia histórica ligada a la mixtificación folclórica y popular). Entre la documentación histórica y el mito idealizado se encuentran los amores de Alfonso XII y la malograda María de las Mercedes, relación que tanto jugo dio ante los ojos de la adoración sentimental del pueblo.

La visión de Andalucía denuncia la herencia de un elemento propio del Romanticismo, en el que esta región suponía el punto fundamental de la visita a España. La llegada a Córdoba incita también al recuerdo del Gran Capitán y sus heroicas gestas; en Granada, adquiere protagonismo María Pineda. Con Cádiz recuerda el año 1810, y los procesos de emancipación de los españoles frente a los franceses y de los chilenos ante su metrópoli; o con Tarifa comenta la figura de Guzmán el Bueno. En muchos casos es una elucubración que ilustra sensaciones y sentimientos producidos a raíz de la contemplación del paisaje, pues para el caso de la envidia menciona a César, Luis XI y Luis XIV. Todo lo expuesto 
sintetiza un tipo de disertación intelectual que complementa la visita, por doble vía: demostrando el carácter instruido del viajero y aspirando a facilitar información suplementaria al lector instruido.

Continúa su viaje y llega a Granada donde admira la Peña de los enamorados y explica para el lector la procedencia de este nombre. Pero quizás quien le arranca alguna de sus mayores ensoñaciones sea la vega granadina, la extensa zona de labranza que acota los márgenes de la ciudad. Con Granada encontramos los pasajes que más se vuelcan en la imaginación, durante su recorrido por el Albaicín, el Generalife y, por supuesto, la Alhambra. Junto a ello, da cuenta de los lugares más populares, como la cuesta de los Gomeles.

En Sevilla, después de recrearse en el paisaje andaluz y recorrer lugares como La Rinconada, accede a la Giralda. Se acercará después a la casa de Pilatos, la fábrica de tabacos, las ruinas de Itálica, el archivo de Indias o la biblioteca colombina. Con Jerez, en suma, conoceremos el origen de su nombre y deambularemos por rincones como la plaza del Arenal, la Cartuja, sus casas blancas, las bodegas (la de los gigantes, la de los Doce Apóstoles y la de la Rotonda) o los viñedos. Y en Cádiz, la torre del Vigía, las plazas de la Mina o de las Delicias y las academias de arte. Tales enumeraciones conforman el tono documental del texto y el valor expositivo.

\section{Pintoresquismo}

La descripción de Lizardi también nos permite acceder a incursiones costumbristas que se acercan a la cosmovisión más pintoresca acerca de España. Entre ellas, por ejemplo, se encuentra la del regateo de precio, unida al carácter de los lugareños franco y llano, directo y espontáneo. En proximidad con el ánimo pintoresquista se ubica la delimitación de tipos, figuras que pueden configurar modelos hueros y comunes, como el galán y la dama o el chalán (en Barcelona). Se alude también a la "pachorra" (p. 25) de la raza hispánica, a excepción de los catalanes que evidencian un espíritu emprendedor fruto del hibridismo cultural por los que allí habitaron. A partir de ahí recorre toda clase de tipos sociales, pues pululan por sus páginas mendigos, gitanos o desharrapados.

En el ámbito del pintoresquismo se halla la descripción de costumbres populares, desde el baile más tradicional hasta los cantos que arrancan el sentir más profundo del pueblo. El flamenco emerge en protagonismo indiscutible, incluso en Barcelona en los cafés cantantes (p. 45). De igual forma, en profusa confusión advierte el gusto sevillano por el baile, sea este un bolero, una danza aragonesa o el mismo flamenco (p. 281).

Entre los tipos que describe figura la beldad cordobesa en todo un estereotipo: ojos negros y grandes, tez brillante y tostada. Por extensión, a partir del carácter andaluz, no duda en incidir en la actitud abierta y comunicativa del español. El carácter expansivo andaluz, propenso a la alegría y al bullicio, es motivo constante, exprimido en capítulos como el dedicado a Sevilla: "La alegría 
que reina constantemente en este pueblo casi llega a lo increíble” (VE, p. 181). Caso peculiar es el sevillano por el crisol de lenguas y nacionalidades que se concentran en la ciudad con motivo de la Semana Santa. Este pasaje, de indudable valor antropológico, nos ofrece una estampa singular de la urbe como punto de encuentro en una festividad en la que lo lúdico y prosaico y lo esencialmente espiritual se mezclan en una comparecencia híbrida. La apariencia de las calles, las características de las cofradías, el deambular de los pasos, la entrega arrobada del público, la vestimenta de los hermanos de las cofradías..., aparecen perfilados con singular fruición. Anotemos lo preciso de los detalles que ofrece, fieles a lo que aconteció en aquella Semana Santa de 1884 (del 6 al 12 de abril) (véase Carrero Rodríguez, 1991): el Miércoles Santo salen las cofradías del Santo Sudario de San Antonio de Padua y las Siete Palabras de San Vicente; el Viernes Santo las del Silencio o el Gran Poder, por la mañana, y Soledad de San Buenaventura, la de Patrocinio, la de San Isidoro, Santa Catalina o Montserrat por la tarde. En Sevilla tendrá ocasión de comentar la situación de los gitanos, lo que conduce a un perfil negativo de lo que él considera como pueblo que ha dado la espalda al progreso y se mueve en un ámbito marginal. De su estampa, nos aporta las creencias del momento de su procedencia egipcia.

Si peculiar era la descripción de la Semana Santa, por el detalle de la incursión y el carácter original de los detalles (una de las primeras muestras descriptivas de tal evento), a la zaga se halla el capítulo XXVIII dedicado a los toros. Empieza con menudencias varias acerca de la disposición del recinto, pero la disertación se permite incluso alusiones a célebres toreros como Frascuelo o Lagartijo. Por los datos que se nos aportan, todo parece indicar que el autor acudió a la corrida del 18 de abril, con toros del ganadero charolés Jean-Pascal Laffitte (El Toreo, 21 de abril de 1884).

A imitación de la crónica taurina, aborda el autor chileno los posos del evento. Ténganse en cuenta las siguientes referencias, cuyo protagonista es Lagartijo en competencia con Frascuelo, en el mismo mes de abril de 1884 en el que Lizardi pasea por Sevilla: alude a la plaza como un circo, a la usanza de la tradición clásica romana (metáfora recurrente en la prensa taurina: El Toreo, 18 de abril de 1884); la incursión de los banderilleros, la bravura del toro (Boletín de loterías y de toros, 21 de abril de 1884), la entrega del público (La lidia, 28 de abril de 1884) y los pases artísticos del torero (Boletin de loterías y de toros, 15 de abril de 1884). Sin que sepamos con total certidumbre si leyó todos o parte de estos periódicos, no es menos evidente la similitud de sus apreciaciones con lo que en la prensa se vertía.

Así pues, Lizardi describe la liturgia en la plaza, desde el aviso de la corneta hasta los ademanes del torero, y finalmente el ofrecimiento de la oreja. No es de menos interés la reflexión sobre una costumbre netamente española que, a su juicio, obedece a instintos bárbaros y es más propia de una nación atrasada que no de un pueblo que mira al progreso (como debería ser el caso del español). Para 
establecer un adecuado contrapunto, introduce un texto de Moratín en defensa de los toros (del que hablaremos de nuevo), con el que pretende mostrar la postura favorable a la fiesta nacional y así adoptar una esmerada y equilibrada distancia.

\section{Madre patria}

Lizardi es consciente de la distancia cultural entre el país visitado y su región de origen. El texto evidencia un empeño de aproximación cultural entre ambas zonas, para lo que procede a la comparación continua. Este método afecta a todos los ámbitos, incluido el literario. En realidad, procura salvar distancias, a veces de manera anacrónica y descontextualizada, con el parangón cultural. Por ello, la obra La Pasionaria, que ve representada en Valencia, se pone en paralelo con el drama de Rodríguez Velasco, insigne dramaturgo chileno. Grandes eventos de su patria como la batalla de Rancagua, surgen de la pluma de Lizardi. El lector chileno, principal destinatario de este texto, recibe comentarios que permiten plasmar una visión de las impresiones del viajero, en un país lejano, aproximadas al contexto de Chile. Por ello las casas jerezanas se ponen en paralelo con las quintas de las afueras de Montevideo (p. 300).

La lejanía geográfica se salva con las incursiones en la peculiaridad chilena, a través de una comparación espuria que relaciona sucesos y obras en un proceso en el que se extraen de su contexto para alcanzar un fin didáctico. Colabora el autor, merced a todo este artificio, en la construcción de una andanza de literaturización de su viaje. Este itinerario adopta las herramientas propias de una incursión iniciática en la que el viajero construye una perspectiva propia de interpretación y reinterpretación de lo que observa; sucede a la manera de lo que comenta Wolfzettel (2005) a través de la dialéctica de distanciamento y separación de la zona de procedencia frente a las tentativas de comprensión e internamiento en el punto de destino. Con ello Lizardi prima la efectividad comunicativa, como si ubicase en posición primordial el horizonte de expectativas del futuro lector. Este diseño compositivo configura el lector virtual de Viaje en España, recreación de las andanzas de un chileno vertebradas especialmente para sus contemporáneos.

\section{Recreación artística y disertaciones literarias}

El autor recurre a la elaboración retórica para embellecer la exposición. Con el símil, plastifica las visiones que se manifiestan en el libro, con lo que Lizardi busca amenizar la lectura pensando de nuevo en ese posible lector del que hablábamos: las casas blancas son como "blancas gaviotas que el navegante divisa a la proximidad del anhelado puerto" (pág. 14); los paseantes de las Ramblas son "como desbandado ejército al asalto de poderosa fortaleza" (p. 20), el asombro es "como tributo de vasallaje" (p. 37), el trovador enamorado se aproxima "como si quisiese hacer coro al himno de las aves" (p. 110), los amantes son "como 
secretos mensajeros de meditada conspiración" (p. 153). El comentario de las reuniones sociales (llenas de vivacidad y compadreo espontáneo) merecerá el encaje literario más logrado y el más encendido empeño por mostrar a los grupos sociales en plena actividad festiva. La metáfora se acerca a la catalogación más literaria del lugar que se visita (así, la realidad es "una severa madrastra de la ilusión”, p. 19). El estilo enumerativo, muy frecuente en Lizardi, permite la rememoración rápida de los rincones descubiertos o de los sentimientos que le han despertado (pp. 14, 290).

Las repeticiones buscan el énfasis expositivo, así en el entusiasmo tras la visita a Barcelona ("Por la primera vez", p. 31). Suponen una pulsión continua sobre el tema, para recalcar el mensaje, como así vemos en diferentes momentos (p.158). Muy sobresaliente es el empeño, como es común en la narrativa de viajes, de imitar el registro conversacional de figuras que pululan por los lugares a los que acude Lizardi. Este afán se mueve entre lo que es un valor testimonial y la estricta ficcionalización de posibles situaciones que engalanan la descripción de los hechos. Leemos conversaciones con el barítono Lalloni sobre el Liceo (p. 42), discusiones sobre la importancia del Río Darro frente al Genil (p. 151), la lectura de la bienaventuranza por parte de una gitana (p. 218), o el joyero y el corredor de casas que debaten sobre la maestría de los toreros Frascuelo y Lagartijo (p. 257). Este último ejemplo nos muestra a un Lizardi que se documenta en la prensa de la época y participa de algunas polémicas del momento. En concreto, debemos remontarnos a abril de 1884 en el número 453 de $\mathrm{La} \mathrm{Se-}$ mana Ilustrada, donde se publica una carta del sr. Luna en la que pone en entredicho la maestría de Lagartijo. Obtendrá respuesta de Raggio en el número 455 de El Toreo, lo que no hizo más que recrudecer los enfrentamientos dialécticos entre los partidarios de ambos toreros. Lizardi, oportunamente distante, recrea la disputa de dos aficionados, otorgando un prudente equilibrio y una postura mesurada.

Además de la simple recreación estilística, interesan especialmente las numerosas alusiones literarias que aparecen en el texto, en ocasiones de soslayo (como la mención a Echegaray en la p. 304). Muy llamativa es la inclinación por las representaciones teatrales, que revelan el gusto del autor por lo dramatúrgico. En el teatro principal de Barcelona ve a la actriz Agar ejecutando el papel de la $\mathrm{Ca}$ mila de Horacio de Corneille (p. 38). Al margen de la descripción física, analiza sus dotes declamatorias, el poder de su voz, y su capacidad para recrear personajes. La Pasionaria de Leopoldo Cano y Masas merece también un largo comentario, una exposición de la trama narrativa y de los rasgos de los personajes principales.

De su gusto es la paráfrasis literaria. La trágica historia de Dido y Eneas (en el libro IV de La Eneida) merece un prolijo comentario; la muerte de Dido, inmolada en la pira en la que quema su amor, nace de la contemplación de la huerta valenciana: «Así, así me complace descender a las sombras. Que este 
fuego devore con sus ojos desde alta mar el cruel troyano y consigo porte la maldición de mi muerte», dice Dido en el texto de Virgilio.

La observación de La Mancha conduce a la casi que inevitable referencia al Quijote. A su vez, introduce la alusión erudita a través de Sismondi. Con él, parece referirse a la Historia de la literatura española que este último publica en 1841, texto de referencia en el siglo XIX en relación con los estudios sobre la gran obra cervantiva. La alusión a Sismondi inicia el excurso en torno a los valores universales del Quijote y el significado de sus actantes.

El afán literario se desborda en múltiples matices, como el significativo caso de la página 130 en la que una extensa elucubración filosófica procura la comprensión sobre el sacrificio humano. En otra línea, la llegada a la Alhambra le facilita el juego de la intertextualidad, con las referencias al álbum de recuerdos de Alejandro Dumas sobre la ciudadela. Sin que lo explicite, Lizardi alude al capítulo XX de De París a Cádiz, y comparte con este una interesante retroalimentación intertextual en la recreación de la zona del Generalife.

En la línea del espíritu romántico, Andalucía ocupa las horas (casi todas ellas) del viaje a España. Más adelante, el camino a Jerez induce a una reflexión sobre la locura y la melancolía, que permite la cita de la hija del conde don Julián (dígase la Cava) y su desventurada desgracia, también la de la shakesperiana Ofelia al borde de la locura deshojando flores, o la Ifigenia de Eurípides (la de Ifigenia en Táurida e Ifigenia en Aulide) desmayándose. Ya en Jerez, la contemplación de su campo provoca que se retraiga hacia un bucolismo virgiliano². En Gibraltar, en el peñón, la vista del horizonte que sinuosamente se pierde a lo lejos le permite recordar las civilaciones antiguas que a lo lejos se pierden, y los que formaron parte de esas culturas, como Aristófanes, Herodoto, Tucídides, Jenofonte, en el mundo griego; o Licofón y Apolonio de Rodas en Alejandría. El caso más notorio de intertextualidad surge con la introducción de la extensa carta de Moratín al príncipe Pignatelli el 25 de julio de 1776, en defensa precisamente de la tauromaquia, un texto que ocupa todo el capítulo XXXVII (pp. 267-278). Del mismo autor procede el amplio poema puesto en boca de Guzmán el Bueno (p. 349), que es recordado al llegar a Tarifa. Se trata de un fragmento de la pieza teatral del mismo nombre que el autor ilustrado compone en 1777.

El escritor chileno combina asimismo el dato histórico con la incursión literaria. La llegada a Vilches introduce los hechos de las Navas de Tolosa y la batalla contra las huestes musulmanas. De inmediato, se procede a una recreación literaria en la que se expone la derrota de Mohamed y sus lágrimas finales. Igual

2 Alude a las églogas virgilianas, y al equilibrio del hombre en la contemplación de la naturaleza: "Buscan ahora los lentos rebaños del valle oscuro la fragante alfombra y todavía el reptil al pie de los castaños encuentra asilo en la verde sombra. En medio de los males más extraños sabiendo que tu labio ni me nombra, yo triste y solo a la planada llego cuando el sol en su cumbre muestra fuego" (Égloga II), 
proceso advertimos con la llegada a Arjonilla y los trágicos sucesos del trovador Macías, al modo de Larra y su obra homónima de 1834.

Por otra parte, la contemplación de los lugares lo conduce al homenaje literario. Ante la vega granadina, introduce la canción "Abén-Hamet al partir de Granada /su corazón destrozado sintió; / y allá, en la Vega, al perderla de vista/ con débil voz su tormento expresó". El texto, del que no se da noticia de su extracción, pertenece a la popular serenata "La Golondrina", compuesta por el mejicano Narciso Serradel en 1863. La tensión intertextual de este caso es de sumo interés por lo que implica de concesión al mundo de hispanoamérica, probable afán por ganarse al lector.

En este empeño de hilar textos literarios llega a la vista de las ruinas de Itálica, que le hacen pensar en los versos de Rodrigo Caro (1573-1647) sobre el mundo romano, "la casa para el César fabricada/¡ay! Yace de lagartos vil morada" (p. 226). Una vez más, el autor omite otros datos que esclarezcan la procedencia del texto (el que nos ocupa procede de la "Canción a las ruinas de Itálica", versos 53-56). Algo similar sucede en la rememoración de Luis de Granada (en lo que parece pensamiento fugaz sobre la Guía de pecadores) y la disertación en relación con el espíritu mundano que "se cierne en esas regiones que plazas parecen" (p. 242).

Muy tangencialmente se detiene en manifestaciones artísticas como la pintura, la escultura o la arquitectura, y también la música. Percibimos una mera constatación del monumento, y un comentario exiguo de aquellos detalles fácilmente observables, sin que se detenga en el comentario razonado de las características de su estilo o los principios propios de sus filiaciones. En la fugaz asimilación de lugares, dentro de esta dinámica, aparece la Catedral de Valencia; o la importancia de Murillo, Alonso Cano o Palomino en la Cartuja granadina. Menciona con prurito de erudición la obra Carmen (no alude a Mérimée, quizás presuponiendo el carácter universal de esta obra) en relación con la fábrica de tabacos sevillana. El catálogo de textos y asuntos engorda con la descripción de otros cuadros como el San Antonio de Murillo (se atiende a la delectación personal y constatación de lo que él cree que plasma, al margen de un comentario estrictamente artístico, p. 237). En Cádiz, advierte igualmente la presencia de valiosas pinturas de Tintoreto, Morales, Rivera o Murillo (p. 339), y rememora esculturas que ha visto en otros viajes como la Gloria Victis de Mercié, obra de 1874 hoy custodiada en Washington.

Las referencias pictóricas se ponen en parangón con impresiones y matizaciones subjetivas, fruto de la experiencia de un viajero que relaciona elementos diferentes de filiación nula o dudosa. Proponemos en tal margen las comparaciones, carentes de cualquier sustento metodológico, entre la obra de Ribalta y la de Miguel Ángel (p. 81). Con todo, aparecen excepciones a la altura del lugar reseñado, como ocurre con la mezquita cordobesa en la que se detiene en las características del patio columnado y la decoración. La disposición de las naves 
y del santuario, los adornos, la iluminación, la riqueza de objetos y el arte suntuario en general que puebla el recinto, contrasta a su parecer con la bárbara decisión, apoyada por Carlos $\mathrm{V}$ en pleno esplendor del imperio español, de cristianizar la mezquita. De igual manera, se detiene en el caso de la Alhambra, por su elevado valor simbólico, de forma que explica el origen de su nombre, y recorre, como si invitara al lector a que fuese con él por sus rincones, el patio de los Arrayanes, el mirador de Lindaraja o la Sala de los embajadores. Otro caso excepcional es el de la catedral de Sevilla, de la que se comentan la sillería del coro o el altar mayor, además de la custodia de plata o el tenebrario de quince brazos, sin que se precise ningún rasgo del estilo en el que se subscriben. Puede deberse al afán divulgador del texto, enfocado a un público amplio que, además, se relaciona con un ámbito geográfico lejano y ajeno. Toma con ello sólidamente fuerza la labor de extrañamiento del viajero, que en arrasadora fuerza de alteridad y distanciamiento se ve inmerso en una cultura modelizada en un prototipo con imprecisos sesgos.

\section{Fin de viaje}

En síntesis, la lectura del texto de Sanhueza Lizardi ofrece un interés notable, desde diferentes puntos:

a. Desde su adscripción a la literatura de los viajes, en la que participa de sus esquemas narrativos. Uno de ellos resulta fundamental: la importancia de Andalucía, como modelo del recorrido por España, a la manera del movimiento romántico.

b. Desde una actitud de distanciamiento que aporte una visión neutral de los lugares visitados. Para ello, procura la indagación sobre las regiones en destellos de variada multiplicidad: económicos, sociales, culturales.

c. Desde el juego de la alteridad y el extrañamiento que acarrea la distancia geográfica y cultural con Hispanoamérica.

d. Desde la misma condición de viaje intelectual (frente al religioso, al que implica un exilio forzado o un éxodo inevitable, o al que emprende una búsqueda de la prosperidad comercial).

e. Desde su misma condición de relato descriptivo que requiere una delimitación detallada de los hechos.

f. Desde las continuas referencias, intencionadamente no cotextualizadas, al mundo de Chile, en procura de un afán didáctico: la comprensión del lector, enhebrando de modo adecuado los hechos con su horizonte de expectativas.

g. Desde la continua cita erudita, palillada con las alusiones históricas y las ricas referencias intertextuales. 
h. Desde, en suma, la propia elaboración del lenguaje, que en una retoricidad intencionada transgrede los límites entre el género testimonial y el literario (en su alma de texto ficcional).

Termina el autor ese viaje de formación en Andalucía. Deja entonces que duerman sus pasos como cierran sus ojos las hojas de Viaje en España. Así dejemos descansar nosostros a estas páginas para que acabe la ruta de las palabras.

\section{BIBLIOGRAFÍA}

Aínsa, F., "Peregrinaciones en la narrativa hispanoamericana del XIX y XX. Entre el viaje iniciático y la búsqueda de raíces", en Julio Peñate Rivero y Francisco Uzcanga Meinecke (eds.), El viaje en la literatura hispánica: de Juan Valera a Sergio Pitol, Madrid, Verbum, 2008, pp. 47-64.

Bordonada, A., Literatura de viajes, Madrid, Universidad Complutense, Servicio de publicaciones, 1995.

Carrizo Rueda, S., Poética del relato de viajes, Kassel, Reichenberger, 1997.

Carrero Rodríguez, J., Anales de las Cofradías Sevillanas, Sevilla, Castillejo, 1991.

Farinelli, A., Apuntes sobre viajes y viajeros por España y Portugal, Establecimiento Tipográfico de Adolfo Brid, 1889.

García Mercadal, J., Viajes de extranjeros por España y Portugal: desde los tiempos más remotos hasta comienzos del siglo XX, Valladolid, Junta de Castilla y León, Consejería de Educación y Cultura, 1999 .

Gasquet, A., "Bajo el cielo protector. Hacia una sociología de la literatura de viajes", en Manuel, Lucena Giraldo y Juan Pimentel (eds.), Diez estudios sobre literatura de viajes, Madrid, Consejo superior de investigaciones científicas, 2006, pp. 31-66.

Lucena Giraldo, M. y J. Pimentel (eds.), Diez estudios sobre literatura de viajes, Madrid, Consejo superior de investigaciones científicas, 2006.

Peñate Rivero, J. y F. Uzcanga Meinecke (eds.), El viaje en la literatura hispánica: de Juan Valera a Sergio Pitol, Madrid, Verbum, 2008.

Romero Tobar, L. y P. Almarcegui (coords.), Los libros de viaje: realidad vivida y género literario, Madrid, Akal, 2005.

Sanhueza Lizardi, R., Viaje en España, París, Librería de Garnier Hermanos, segunda edición, 1889.

Münzer, J. y H. Münzer, Viaje por España y Portugal, 1494-1495, Polifemo, 2002.

Wolfettel, F., "Relato de viaje y estructura mítica”, en Leonardo Romero Tobar y Patricia Almarcegui (coords), Los libros de viaje: realidad vivida y género literario, Madrid, Akal, 2005, pp. 10-24.

Nombre del autor: Javier López Quitáns

Dirección-e:_ javierlopezquintans@yahoo.es

Dirección postal: $\quad$ Calle B, 75, 4 A, 36500 Lalín (Pontevedra)

Fecha de recepción: 18/11/2011

Fechade aceptación: 11/12/2012 
